Revista de

Contabilidade e

Organizações

www.rco.usp.br
DOI: http://dx.doi.org/10.11606/issn.1982-6486.rco.2018.137077
Journal of

Accounting and

Organizations

\title{
Endividamento e decisões contábeis: a relação não linear entre dívida e quali- dade dos lucros
}

\author{
Indebtedness and Accounting Choices: The Non Linear Relation between Debt and Earnings Quality \\ Cristiano Machado Costa ${ }^{\mathrm{a}}$; Adriana Machado Matte ${ }^{\mathrm{a}}$; Danilo Soares Monte-Mor ${ }^{\mathrm{b}}$ \\ ${ }^{a}$ Universidade do Vale do Rio dos Sinos
}

${ }^{b}$ Fucape Business School

Palavras-chave

Qualidade dos Lucros.

Dívida de Longo Prazo.

Não linearidade.
Keywords

Earnings Quality.

Long Term Debt.

Non Linearity.
Informações do Artigo

Recebido: 16 de agosto de 2017

Aceito: 06 de maio de 2018

Publicado: 23 de maio de 2018

\section{Resumo}

Os contratos de dívidas das empresas podem gerar diferentes incentivos para os gestores praticarem o chamado gerenciamento de resultados. De acordo com a maioria dos estudos presentes na literatura, empresas buscariam reduzir os accruals discricionários para reduzir assimetria de informação e incorrer em menores custos de financiamento. Outros estudos, porém, apontam que empresas com níveis muito elevados de endividamento podem fazer o contrário, aumentando os accruals discricionários para não incorrer em cláusulas restritivas (covenants). Considerando essas duas teorias, este artigo propõe uma relação não linear entre dívida e o componente discricionário dos lucros para as empresas listadas na BM\&FBOVESPA entre 2008 e 2015. As evidências indicam uma relação positiva entre baixos níveis de dívida e a qualidade dos lucros, mas negativa para níveis maiores de dívida. Esse resultado sugere que em níveis elevados de endividamento, é preferível diminuir a qualidade dos lucros a incorrer em perdas por violações contratuais. Análises adicionais indicam que a relação não linear encontrada está relacionada à dívida de longo prazo, e não à de curto prazo.

\begin{abstract}
Corporate debt contracts generate different incentives for managers to engage in earnings management. According to many studies in the literature, companies would seek to decrease discretionary accruals to decrease information asymmetry and to incur in lower funding costs. Other studies, however, point out that companies with high debt levels can do the opposite by increasing discretionary accruals to avoid covenants. Given these two theories, this paper proposes a nonlinear relationship between debt and the discretionary component of earnings for companies listed on BM\&FBOVESPA from 2008 to 2015. Evidences indicate a positive relationship between low debt levels and earnings quality, but negative for higher debt levels. It suggests that in higher debt levels, it is preferable to decrease earnings quality than to incur in losses due to contractual breaches. Further analysis indicates that such nonlinear relationship is related to long-term debt rather than to short-term debt.
\end{abstract}

\section{Implicações práticas}

A relação não linear entre dívida e o componente discricionário dos lucros das empresas de capital aberto indica uma redefinição dos contratos de dívida para proteção ao credor. A análise do ponto de inflexão auxiliaria agentes financiadores (bancos e credores) a readequarem as cláusulas de proteção ou taxas de juros que compensem os riscos associados à informação contábil.

Copyright (C) 2018 FEA-RP/USP. Todos os direitos reservados

\section{INTRODUÇÃO}

Os contratos de dívida, além de gerarem informações que auxiliam na avaliação de decisões operacionais, servem como mecanismo de disciplina de gestores (Harris \& Raviv, 1990). Em particular, os covenants presentes nos contratos de dívida têm potencial para limitar o engajamento do gestor em atividades de maior risco (Leland, 1994).

Autor Correspondente: Tel. (51) 3591-1122

E-mail: cristianocosta@unisinos.br (C. M. Costa); adriamatte@unisinos.br (A. M. Matte); danilo@fucape.br (D. S. Monte-Mor)

Universidade do Vale do Rio dos Sinos. Avenida Unisinos, 950 - Cristo Rei, São Leopoldo - RS, 93022-000, Brasil 
Nesse caso, as informações presentes em tais contratos podem afetar o comportamento dos gestores, a política operacional das empresas e, portanto, a forma com que os lucros são reportados (Francis et al., 2005; Graham, Li \& Qiu, 2008; Bharath, Sunder e Sunder ,2008). Em firmas com elevado endividamento verifica-se um aumento no componente discricionário dos lucros (Sengupta, 1998). Nessas empresas, os gestores possuem incentivos para gerenciar resultados e reportar lucros que diminuam a probabilidade de violação de covenants contábeis (Grossman \& Hart, 1982; Watts \& Zimmerman, 1986; Healy \& Wahlen, 1999; Defond \& Jiambalvo, 1994; Sun \& Rath, 2008). Já nos casos de baixo endividamento, as firmas são mais propensas a reportar lucros com um menor componente discricionário para reduzir os custos de financiamento da dívida e aumentar o nível da informação sobre fluxos de caixa futuros (Smith, 1993; Ghosh \& Moon, 2010).

Essas evidências indicam a relação entre endividamento e nível do componente discricionário (ou simplesmente accruals) como sendo não linear e côncava. Ou seja, à medida que as empresas elevam seus níveis de endividamento, reduzem os níveis de accruals, o que seria decorrente de uma tentativa de reduzir custos de financiamento (Diamond, 1991; Billett, King e Mauer, 2007). Porém, a partir de certo nível de endividamento, devido às cláusulas de covenants, os ganhos advindos da redução de custos da dívida seriam mitigados pelos riscos de não cumprir as cláusulas, surgindo incentivos ao aumento dos accruals (Sweeney, 1994; DeFond \& Jiambalvo, 1994; Sun \& Rath, 2008).

Compreender se existe tal relação não linear entre endividamento e accruals, ou se a mesma possui relação negativa e linear, como defendido por Dechow et al., 2010, é extremamente relevante para os tomadores de decisão que utilizam métodos baseados em informações sobre lucros e fluxos de caixa passados. A forma côncava apontaria níveis de endividamento nos quais os accruals são mais elevados e, portanto, as estimativas de fluxo de caixa mais imprecisas.

Essa relação côncava foi mostrada por Ghosh e Moon (2010) para o mercado norte-americano entre 1998 e 2004. Entretanto, diversas características do mercado americano o diferenciam de mercados emergentes, como é o caso do mercado brasileiro. Em especial, o acesso ao mercado de capitais e os prazos para financiamentos de longo prazo (via dívidas e via debêntures), ambos muito menores e mais restritos no mercado brasileiro (Funchal \& Monte-Mor, 2016). No caso do mercado de capitais, as empresas brasileiras possuem em média níveis de endividamento mais elevados do que as empresas americanas, o que tornaria os efeitos do endividamento no gerenciamento de resultados ainda mais relevantes. Quando o endividamento é elevado, os prazos de financiamento mais curtos do mercado brasileiro para contratos de longo prazo poderiam levar a um menor efeito das cláusulas de covenants na escolha por gerenciar os resultados quando o endividamento é elevado.

Gráfico 1. Relação entre Nível de Endividamento e Accruals

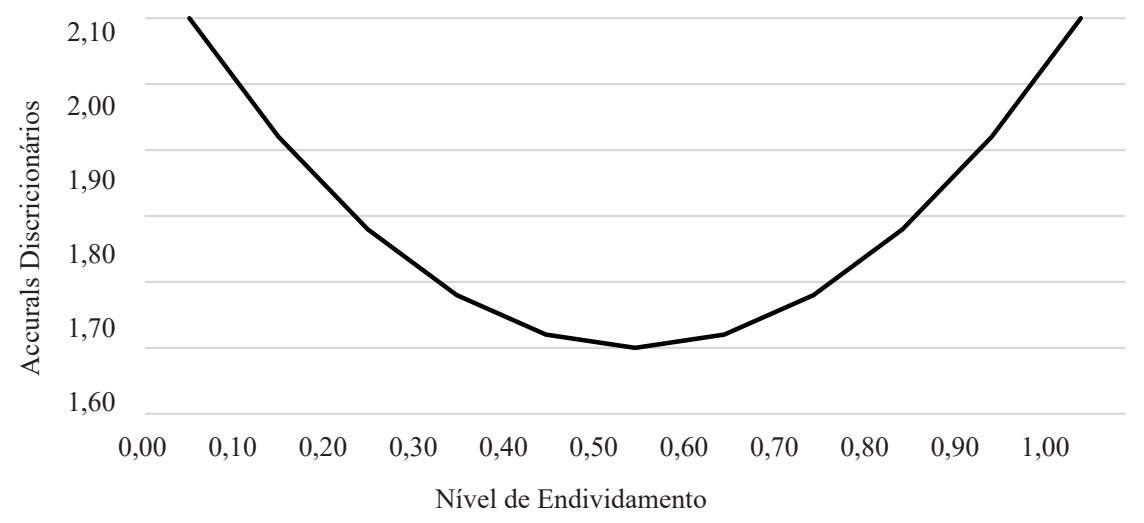


Para validar os resultados de Ghosh e Moon (2010) no cenário nacional, este artigo testa a relação não linear entre dívida e o componente discricionário dos lucros no mercado brasileiro. Tal relação também foi testada na Malásia por Zamri, Rahman e Isa (2013), onde encontraram uma relação negativa, ou seja, quanto maior o endividamento, menores os accruals. A partir de dados de empresas brasileiras listadas na BM\&FBOVESPA no período de 2008 a 2015, verifica-se por meio do Gráfico 1 evidências iniciais da relação não linear entre dívida e accruals no mercado brasileiro.

Outro aspecto, apontado por Fung e Goodwin (2013, é que a relação entre accruals e endividamento pode variar de acordo com maturidade da dívida. Para o mercado americano, os autores apontam que a relação é positiva para dívidas de curto prazo, porém muito mais fraca para dívidas longas. Contudo, os autores não investigam a possibilidade de não linearidade. No mercado brasileiro, tal como apontado por Silva (2008), as empresas com dívidas de longo prazo estão sujeitas a diversas cláusulas de covenants, por isso o segundo ponto de contribuição deste artigo é verificar se a relação não linear entre endividamento e nível dos accruals se mantém quando segregamos a dívida total entre dívida de curto e longo prazo, complementando o trabalho de Fung e Goodwin (2013).

O estudo foi feito com empresas listadas na BM\&FBOVESPA no período de 2008 a 2015. Para estimar a qualidade dos lucros foram considerados os modelos de Jones (1991), Jones modificado de Dechow, Sloan e Sweeney (1995), Dechow e Dichev (2002) e McNichols (2002), ambos baseados na magnitude do componente discricionário do lucro. Um modelo quadrático foi utilizado para mensurar a não linearidade entre dívida e accruals. Para controlar a heterogeneidade existente entre as empresas da amostra utilizou-se, além dos controles presentes em Ghosh e Moon (2010), outras variáveis que explicam a relação entre o nível da dívida e a qualidade dos lucros no mercado brasileiro. Como teste de robustez, foi realizada uma regressão segmentada, utilizando-se uma especificação não linear por partes, na qual a dívida e a dívida ao quadrado foram incluídas na mesma regressão.

Na sequência, as análises foram feitas separando-se a dívida total entre dívida de curto e de longo prazo. Isso por que, se a empresa decide incorrer em custos associados ao aumento do gerenciamento em situações de auto endividamento, então é mais provável que tais custos sejam menores que os custos gerados por problemas de antecipação de dívidas de longo prazo via quebra de cláusulas contratuais.

\section{FUNDAMENTAÇ̃̃O TEÓRICA}

Entre as várias abordagens sobre a teoria de agência, desenvolvida por Fama e Jensen (1983), Jensen e Meckling (1976), entre outros, esta pode ser entendida pelo problema existente entre a divergência de interesses entre os proprietários das empresas (acionistas) e os gestores que a administram. Observa-se que a cisão entre controle e propriedade acontece no momento em que a sociedade por ações multiplica seus proprietários e o controle fica concentrado nas mãos de diretores ou gerentes.

Para garantir a sobrevivência de uma organização faz-se necessário um equilíbrio entre as decisões dos gestores e os interesses dos acionistas, conforme destacam Fama e Jensen (1983). Contratos bem escritos, que delimitem a ação da gestão e definam uma política de incentivos, podem minimizar, por exemplo, a prática do gerenciamento de resultados. Neste contexto, a contabilidade exerce a função não só de registrar os valores recebidos dos investidores ou credores, mas também de informar e monitorar a forma com que esses recursos foram alocados (Bharath et al.,2008; Dichev et al., 2012).

Embora a contabilidade atue como um sistema gerador de informações econômicas da empresa por meio da divulgação dos relatórios contábeis, notas explicativas e outras divulgações voluntárias (Healy \& Palepu, 2001), a contabilidade também pode ser utilizada como instrumento de manipulação gerencial, uma vez que o gestor pode fazer escolhas contábeis que alterem o resultado da empresa em determinado período, com a finalidade de obter ganhos particulares ou atender a expectativas contratuais (Dichev et al., 2012).

A literatura apresenta evidências de que a qualidade do resultado pode depender de fatores como o nível de governança e o desempenho operacional (Chiang, Kleinman, \& Lee, 2017), as expectativas de mercado (Cormier, Demaria, \& Magnan, 2017), o nível de dívida (Bharath et al.,2008), dentre outros. Em todas essas análises, na presença de gerenciamento de resultados via discricionariedade dos lucros, verifica-se um aumento dos custos para a empresa associados à diminuição da qualidade dos lucros e de sua capacidade em prever alterações futuras do fluxo de caixa (Dechow et al., 2010).

A decisão de incorrer em tais custos, entretanto, nem sempre é favorável aos acionistas minoritários e pode estar associada ao conflito de agência existente a partir da cisão entre controle e propriedade (Desender et al., 2013). 
Nesse sentido, mecanismos que atuem como disciplinadores e monitorem as decisões gerenciais podem delimitar a ação da gestão. O nível de endividamento da empresa é um fator que pode influenciar positivamente a qualidade dos lucros, tal como evidenciado nos estudos de Grossman e Hart (1982), Jensen (1986), Diamond (1991), Sengupta (1998), Francis et al. (2005), Graham, Li e Qiu (2008), Bharath et al. (2008) e Ghosh e Moon (2010). De acordo com esta vertente da literatura, os detentores da dívida exigem informações financeiras de alta qualidade, especialmente sobre os lucros, a fim de verificar a solvência da empresa. Alguns bancos privados, por exemplo, , fazem um alto investimento no monitoramento dos mutuários e estabelecem cláusulas contratuais restritivas nos contratos da dívida para as empresas que apresentam pior qualidade nos relatórios contábeis (Bharath et al., 2008). Nesse caso, empresas com menor qualidade do lucro, em média, passam a incorrer em aumentos dos custos de financiamento, bem como de monitoramento por parte dos credores (Ghosh \& Moon, 2010).

Ao tomar recursos emprestados, as empresas ficam sujeitas ao cumprimento de cláusulas previstas nos contratos dos empréstimos (covenants) que podem estabelecer relação com números contábeis (covenants contábeis). Por exemplo, diversos bancos utilizam a relação EBITDA sobre Dívida total como cláusula restritiva em contratos de dívida como mecanismo de incentivo e como forma de garantir a capacidade de pagamento da empresa (Citron, 1992). Nesse caso, a dívida e as exigências dela decorrentes podem ser um motivo para o gerenciamento de resultados, como observado por Watts e Zimmerman (1986), Healy e Wahlen (1999), Defond e Jiambalvo (1994), Sun e Rath (2008) e Bharath et al. (2008), tendo em vista que a gestão poderá fazer escolhas contábeis para alcançar números desejados e, portanto, influenciar um ou mais dos arranjos operacionais da empresa. Jha (2013), por exemplo, aponta que gestores aumentam os níveis de accruals em trimestres próximos ao vencimento de covenants, evidenciando o comportamento oportunista revisto pela teoria de agência (Jensen \& Meckling,1976).

Dadas às evidências apresentas, espera-se, portanto, que a dívida tenha uma relação não-linear com a qualidade dos lucros, Ou seja, espera-se que empresas com baixos níveis de endividamento tenham incentivo à aumentarem a qualidade dos lucros reportados, com objetivo de obterem acesso ao crédito mais barato, mas que empresas com altos níveis de endividamento tenham incentivos à reportarem lucros de menor qualidade e com um maior componente discricionário, buscando atender às cláusulas de covenants. Especificamente, formula-se a seguinte hipótese:

H1: A relação entre o volume de endividamento e a qualidade dos lucros é não linear

Tal como mencionado, a rigidez na vinculação dos contratos da dívida pode resultar no gerenciamento de resultados, uma vez que os custos contratuais advindos de quebras contratuais podem superar os custos da baixa qualidade dos lucros (Ghosh \& Moon, 2010). Sendo assim, empresas com elevado grau de endividamento, e com um perfil de dívida que contenha cláusulas punitivas como os covenants, tenderão a optar por gerenciar os resultados. Estas cláusulas contratuais que permitem a antecipação da dívida estão, em geral, associadas às dívidas de longo prazo. Fung \& Goodwin (2013) já encontraram evidências de que a relação entre accruals e endividamento pode variar de acordo com maturidade da dívida.

Silva (2008) encontrou evidências de que as empresas brasileiras de capital aberto, que tenham dívidas de longo prazo, estão sujeitas a uma série de covenants contábeis. Sendo o Brasil um país com leis baseadas no modelo code law e com baixo nível de efetividade jurídica (Almeida \& Dalmácio, 2015; Lopes \& Walker, 2008), é esperado que contratos de maior prazo tragam cláusulas que busquem reduzir os riscos de crédito. Além disso, a partir de 2010, com a adoção das IFRS no Brasil, o número de contratos com covenants baseados em dados contábeis (ou financeiros) permaneceu em uso e houve crescimento de covenants não financeiros (Beiruth et al., 2017). Os autores apontam que esse pode ser um efeito não só da adoção das IFRS, mas também uma reação do mercado brasileiro aos efeitos da crise de 2008.

Por essa razão, espera-se que no contexto brasileiro a relação não linear existente entre dívida e qualidade dos lucros esteja, em grande parte, associada à dívida de longo prazo, e não à de curto prazo. Formalmente, tem-se a seguinte hipótese:

H2: A relação não linear entre o volume de endividamento e a qualidade dos lucros está associada à dívida de longo prazo, e não à de curto prazo. 


\section{DADOS E MODELO}

A população deste estudo foi constituída pelas companhias abertas listadas na BM\&FBOVESPA que não pertencessem ao setor financeiro e de seguros devido à especificidade das informações contábeis desses setores. Os dados da amostra foram obtidos a partir das demonstrações contábeis referentes ao período de 2008 a 2015, excluindo-se as empresas cujos demonstrativos não apresentaram dados completos. A amostra resultou em 198 empresas no período de análise.

As métricas escolhidas para mensurar a qualidade dos lucros foram os accruals discricionários. Para tanto utilizou-se os modelos de Jones (1991) e Jones modificado a fim de separar o componente discricionário dos accruals totais, já que os modelos relacionam a quantidade de accruals normais (não discricionários) e a quantidade total de accruals. Os resíduos resultantes destas regressões, representados pelo erro $(\varepsilon)$ em seu valor absoluto, indicam os níveis de accruals discricionários. Tal como em Jones (1991) e em Dechow, Sloan e Sweeney (1995), tais modelos de accruals foram estimados ano a ano (cross section).

Além disso, estimou-se os accruals discricionários por meio da relação entre capital de giro no fluxo de caixa operacional realizado, seguindo as metodologias desenvolvidas por Dechow e Dichev (2002) e McNichols (2002). Tais modelos não separam os accruals discricionários daqueles que possam ser oriundos de manipulação gerencial. A qualidade dos accruals é medida por meio dos resíduos absolutos do capital de giro regredido em cross section no fluxo de caixa de $\mathrm{t}-1, \mathrm{t}$ e $\mathrm{t}+1$. Nesse caso, quanto maior o resíduo, menor a qualidade dos accruals.

Tabela 1. Modelos utilizados para estimar os resíduos dos accruals

\begin{tabular}{|c|c|c|c|}
\hline Equação & Modelo & Forma de Cálculo & Método \\
\hline 1 & $\begin{array}{l}\text { Jones } \\
(1991)\end{array}$ & $\begin{array}{l}\mathrm{AC}_{\mathrm{it}} / \mathrm{A}_{\mathrm{it}-1}=\alpha / \mathrm{A}_{\mathrm{it}-1}+\beta_{1}\left[\Delta \mathrm{ROL}_{\mathrm{it}} / \mathrm{A}_{\mathrm{it}-1}\right]+ \\
\beta_{2}\left[\operatorname{Imob}_{\mathrm{it}} / \mathrm{A}_{\mathrm{it}-1}\right]+\varepsilon_{\mathrm{it}}\end{array}$ & $\begin{array}{l}\text { Busca o componente discricionário } \\
\text { das provisões totais. }\end{array}$ \\
\hline 2 & $\begin{array}{l}\text { Jones } \\
\text { Modif. } \\
\text { (1995) }\end{array}$ & $\begin{array}{l}\mathrm{AC}_{\mathrm{it}} / \mathrm{A}_{\mathrm{it}-1}=\alpha / \mathrm{A}_{\mathrm{it}-1}+\beta_{1}\left(\left[\Delta \mathrm{ROL}_{\mathrm{it}} / \mathrm{A}_{\mathrm{it}-1}\right]-\right. \\
\left.\left[\Delta \mathrm{CR}_{\mathrm{it}} / \mathrm{A}_{\mathrm{it}-1}\right]\right)+\beta_{2}\left[\operatorname{Imob}_{\mathrm{it}} / \mathrm{A}_{\mathrm{it}-1}\right]+\varepsilon_{\mathrm{it}}\end{array}$ & $\begin{array}{l}\text { Inclui as contas a receber do período } \\
\text { ao modelo de Jones (1991). }\end{array}$ \\
\hline 3 & $\begin{array}{l}\text { Dechow } \\
\text { e Dichev } \\
(2002)\end{array}$ & $\begin{array}{l}\Delta \mathrm{CG}_{\mathrm{it}} / \mathrm{ATM}_{\mathrm{it}}=\beta_{0}+\beta_{1}\left[\mathrm{FCO}_{\mathrm{it}-1} / \mathrm{ATM}_{\mathrm{it}}\right]+ \\
\beta_{2}\left[\mathrm{FCO}_{\mathrm{it}} / \mathrm{ATM}_{\mathrm{it}}\right]+\beta_{3}\left[\mathrm{FCO}_{\mathrm{it}+1} / \mathrm{ATM}_{\mathrm{it}}\right]+\varepsilon_{\mathrm{it}}\end{array}$ & $\begin{array}{l}\text { Os resíduos, que não estão } \\
\text { relacionados às realizações do fluxo } \\
\text { de caixa, são a medida de qualidade } \\
\text { do lucro. }\end{array}$ \\
\hline 4 & $\begin{array}{l}\text { McNichols } \\
(2002)\end{array}$ & $\begin{array}{l}\Delta \mathrm{CG}_{\mathrm{it}} / \mathrm{ATM}_{\mathrm{it}}=\beta_{0}+\beta_{1}\left[\mathrm{FCO}_{\mathrm{it}-1} / \mathrm{ATM}_{\mathrm{it}}\right]+ \\
\beta_{2}\left[\mathrm{FCO}_{\mathrm{it}} / \mathrm{ATM}_{\mathrm{it}}\right]+\beta_{3}\left[\mathrm{FCO}_{\mathrm{it}+1} / \mathrm{ATM}_{\mathrm{it}}\right]+\beta_{4}\left[\Delta \mathrm{ROL}_{\mathrm{it}} /\right. \\
\left.\mathrm{ATM}_{\mathrm{it}}\right]+\beta_{5}\left[\mathrm{Imob}_{\mathrm{it}} / \mathrm{ATM}_{\mathrm{it}}\right]+\varepsilon_{\mathrm{it}}\end{array}$ & $\begin{array}{l}\text { Combina os modelos de Jones } \\
\text { (1991) e Dechow e Dichev (2002). }\end{array}$ \\
\hline
\end{tabular}

Fonte: Elaborada pelos autores.

$\mathrm{AC}=$ accruals totais; $\mathrm{A}=$ ativos totais; $\mathrm{ATM}=$ ativo total médio; $\Delta \mathrm{ROL}=$ variação da receita operacional líquida de vendas; $\Delta \mathrm{CR}=$ variação de contas a receber; $\mathrm{Imob}=$ saldo de ativo imobilizado, intangível e diferido (brutos); $\Delta \mathrm{CG}=$ Variação do capital de giro; FCO = Fluxo de caixa operacional e $\varepsilon=$ Termo de erro. Subscritos: empresa i, ano t.

Cada modelo de accruals (ver Tabela 1) foi estimado para cada ano da amostra. Este procedimento foi adotado, pois entendemos que não existe um número de empresas suficientemente grande em cada setor. Dessa forma, os modelos foram estimados ano a ano, utilizando-se todas as empresas. Esta abordagem também implica que é estimado um intercepto para cada ano. Assim, quaisquer preocupações quanto a mudança nos níveis gerais dos accruals resultantes da adoção do IFRS são mitigadas, já que os interceptos de cada modelo em cada ano, capturam esse efeito a cada estimação.

Mesmo que algumas evidências apontem que a adoção do IFRS no Brasil resultou em mudança do nível dos accruals discricionários (como apontado em Martinez, 2013 p. 21-22), ainda não existe um consenso, uma vez que há resultados de ausência de efeito, como em Joia (2012) e Joia e Nakao (2014), e de aumento, como em Klann (2011) e Cupertino (2013). O uso de estimativas ano a ano, reduz esse efeito caso ele tenha sido uma mudança no nível dos accruals (ver Doukakis, 2014); Soderstrom e Sun, 2007) e Van Tendeloo e Vanstraelen 2005).

Uma vez estimados os resíduos em cada um dos modelos, estimou-se a relação entre a qualidade dos lucros e o nível de endividamento por meio da equação:

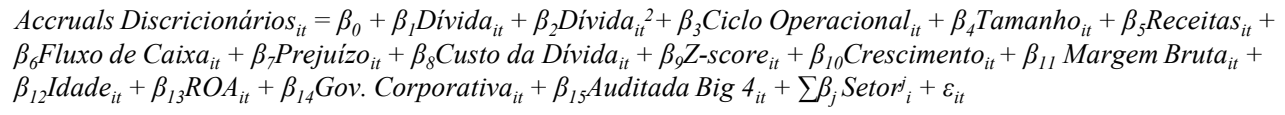


A variável independente dívida foi adicionada ao modelo em nível e na forma quadrática para que fosse testada a relação não linear entre dívida e a variável dependente, accruals discricionários. Conforme H1 espera-se que tal relação seja não linear e, portanto, que o coeficiente estimado $\beta 2$ seja estatisticamente significativo.

Para que fosse possível reduzir a heterogeneidade existente na amostra, foram utilizadas variáveis de controle tal como em Ghosh e Moon (2010), sendo elas: variáveis operacionais (Ciclo Operacional, Tamanho, Receita, Fluxo de Caixa, Dummy indicativa de prejuízo e Custo da Dívida); o Z-Score como indicador de saúde financeira e; fatores de crescimento (Crescimento e Margem Bruta). Adicionalmente, foram utilizadas outras variáveis que explicam a relação entre o nível da dívida e a qualidade dos lucros no contexto brasileiro (Idade da firma, ROA, Níveis de Governança Corporativa, Dummy indicativa de BIG4). As definições das variáveis independentes e de controle bem como as respectivas referências seguem descritas na Tabela 2.

Tabela 2. Variáveis independentes e variáveis de controle

\begin{tabular}{|c|c|c|c|}
\hline Variável & Sinal & Fonte & Forma de Cálculo \\
\hline \multicolumn{4}{|l|}{ Independentes } \\
\hline Dívida & - & $\begin{array}{l}\text { Dechow et al. }(2010) \text {, } \\
\text { Dechow e Dichev } \\
\text { (2002), Ghosh \& Moon } \\
(2010)\end{array}$ & Dívida $_{\mathrm{it}}=\left(\right.$ EmpFinCP $_{\mathrm{it}}+$ EmpFinLP $\left._{\mathrm{it}}\right) /$ Ativo $_{\mathrm{it}}$ \\
\hline Dívida $^{2}$ & + & Ghosh \& Moon (2010) & Dívida $_{\text {it }}$ elevada ao quadrado \\
\hline \multicolumn{4}{|l|}{ Controle } \\
\hline Ciclo Operacional & + & $\begin{array}{l}\text { Dechow et al. }(2010) \\
\text { Dechow e Dichev } \\
(2002)\end{array}$ & 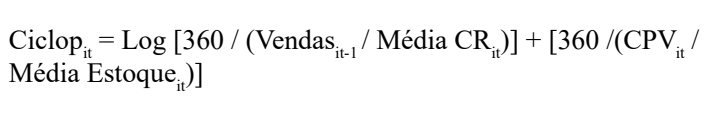 \\
\hline Tamanho & - & $\begin{array}{l}\text { Dechow et al. (2010), } \\
\text { Francis et al. }(2005)\end{array}$ & $\operatorname{Tamanho}_{\mathrm{it}}=\log \left(\right.$ Ativo $\left._{\mathrm{it}}\right)$ \\
\hline Receita & - & $\begin{array}{l}\text { Dechow et al. }(2010) \\
\text { Dechow e Dichev } \\
(2002)\end{array}$ & Receita $_{\text {it }}=$ Receita $_{\text {it }} /$ Ativo $_{\text {it }}$ \\
\hline Fluxo de Caixa & - & $\begin{array}{l}\text { Dechow et al. }(2010) \\
\text { Dechow e Dichev } \\
(2002)\end{array}$ & Fluxo de Caixa $_{i t}=\mathrm{FCO}_{\mathrm{it}} / \mathrm{ATM}_{\mathrm{it}}$ \\
\hline Prejuízo & + & $\begin{array}{l}\text { Dechow et al. (2010), } \\
\text { Francis et al. }(2005)\end{array}$ & Dummy: 1 = prejuízo; zero $=$ lucro \\
\hline Custo da Dívida & + & $\begin{array}{l}\text { Ghosh \& Moon (2010), } \\
\text { Francis et al. }(2005)\end{array}$ & Custo da dívida ${ }_{\mathrm{it}}=$ Desfin $_{\mathrm{it}} /$ DívidaM $_{\mathrm{it}}$ \\
\hline Z-score de Altman & - & Ghosh \& Moon (2010) & $Z=-1,84-0,51 X_{1}+6,32 X_{3}+0,71 X_{4}+0,56 X_{5}$ \\
\hline Crescimento & + & Dechow et al. (2010) & Crescimento $=\left(\right.$ Vendas $_{\mathrm{it}} /$ Vendas $\left._{\mathrm{it}-1}\right)-1$ \\
\hline Margem Bruta & - & $\begin{array}{l}\text { Dechow et al. (2010), } \\
\text { Healy e Wahlen (1999) }\end{array}$ & Margem Bruta ${ }_{i t}=$ Lucro Bruto $_{i t} /$ Receita $_{i t}$ \\
\hline Idade & + & $\begin{array}{l}\text { Dechow et al. }(2010) \text {, } \\
\text { Gu, Lee e Rosett }(2005)\end{array}$ & Dados disponíveis na CVM - Data t da observação \\
\hline ROA & - & $\begin{array}{l}\text { Dechow et al. }(2010) \\
\text { Dechow e Dichev } \\
(2002)\end{array}$ & ROA $_{i t}=$ Lucro Líquido $_{i t} /$ Ativo Total $_{i t}$ \\
\hline Gov. Corporativa & - & $\begin{array}{l}\text { Dechow et al. (2010), } \\
\text { Martinez (2013) }\end{array}$ & Dummy: 1 = pertence ao Novo Mercado; zero = Não \\
\hline Auditada por Big 4 & - & $\begin{array}{l}\text { Dechow et al. (2010), } \\
\text { Martinez (2013) }\end{array}$ & Dummy: 1 = Auditada por Big 4; zero = Não \\
\hline Setor & $+/-$ & Controle & Foram criadas 19 dummies para os setores da amostra \\
\hline
\end{tabular}

Fonte: Elaborada pelos autores.

EmpFinCP= empréstimos de curto prazo; EmpFinLP= empréstimos de longo prazo; Ciclop = Ciplo operacional; Vendas= receita de venda; Média $\mathrm{CR}=$ Média de contas a receber; $\mathrm{CPV}=$ custo do produto vendido; Média Estoque = média de estoques; FCO = Fluxo de Caixa operacional; ATM = Ativo total médio; Desfin = Despesa financeira; DívidaM = Dívida total média; X1 = Capital de Giro Líquido/ Ativo; X3 = Lucro antes de Juros e Impostos /Ativo; X4 = Patrimônio Líquido /Ativo; X5 = Vendas/Ativo. Subscritos: empresa i, ano t. Nota: Os sinais esperados das variáveis foram definidos conforme os seguintes artigos: Dechow e Dichev (2002), Francis et al. (2005), Gu, Lee e Rosett(2005), Ghosh\&Moon(2010), HealyeWahlen(1999), Martinez(2013)eDechowetal.(2010), especialmenteaSeção5 desteúltimoartigo. 
Cabe ressaltar que os modelos estimados incluem dummies de setor (uma para cada um dos 19 setores da amostra) mas não são incuídas dummies de anos, pois os modelos de accruals já foram estimados ano a ano. Assim, quaisquer variações nos níveis dos accruals oriundos de variações comuns às empresas em dado ano, já terá sido capturada pelas estimativas dos accruals. Os modelos estimados atendem ao requerimento de ausência de muticolinearidade, pressuposto verificado através de testes VIF. Os desvios-padrões estimados foram corrigidos para heterocedasticidade e autocorrelação.

As médias estatísticas foram obtidas após winsorizar os dados a 1\% e 99\%, para reduzir o efeito de valores discrepantes nas observações e permitir comparabilidade com outros resultados da literatura. A Tabela 3 apresenta as estatísticas descritivas.

Tabela 3. Estatísticas Descritivas

\begin{tabular}{|c|c|c|c|c|c|}
\hline & Obs. & Média & Desvio padãro & Min & $\operatorname{Max}$ \\
\hline \multicolumn{6}{|l|}{$\begin{array}{l}\text { Resíduos por } \\
\text { modelo }\end{array}$} \\
\hline Jones & 1256 & 0,079113 & 0,121976 & 0,0001149 & 1,789235 \\
\hline Jones Modificado & 1256 & 0,080810 & 0,125993 & 0,0001503 & 1,812205 \\
\hline Dechow e Dichev & 1049 & 0,064163 & 0,073361 & 0,0000761 & 0,672447 \\
\hline $\begin{array}{l}\text { Dechow e Dichev } \\
\text { Modificado }\end{array}$ & 1049 & 0,058465 & 0,066107 & 0,0001036 & 0,601141 \\
\hline \multicolumn{6}{|c|}{ Variáveis de Controle } \\
\hline Dívida & 1256 & 0,317113 & 0,186979 & 0,0000401 & 2,428471 \\
\hline Ciclo Operacional & 1256 & 4,764208 & 0,87268 & $-1,679977$ & 9,636482 \\
\hline Tamanho & 1256 & 14,63718 & 1,611414 & 9,981929 & 18,70509 \\
\hline Receita & 1256 & 0,7159337 & 0,5471304 & 0,0208878 & 5,837755 \\
\hline Fluxo de Caixa & 1256 & 0,0735159 & 0,0959118 & $-1,17195$ & 0,434859 \\
\hline Prejuízo & 1256 & 0,2300955 & 0,4210614 & 0 & 1 \\
\hline Custo da dívida & 1256 & 1,428304 & 33,87979 & $-0,4095891$ & 1192,12 \\
\hline Z-score & 1256 & 0,723397 & 0,597284 & $-0,8963824$ & 5,528129 \\
\hline Crescimento & 1256 & 0,178848 & 1,423779 & $-0,9726202$ & 48,02996 \\
\hline Margem Bruta & 1256 & 0,3115392 & 0,1975047 & $-0,5206292$ & 1 \\
\hline Idade & 1256 & 20,4371 & 14,94081 & 2 & 78 \\
\hline ROA & 1256 & 0,0374563 & 0,1345675 & $-1,515778$ & 1,019286 \\
\hline Gov. Corporativa & 1256 & 0,383758 & 0,4864938 & 0 & 1 \\
\hline Auditada por Big 4 & 1256 & 0,7428344 & 0,4372456 & 0 & 1 \\
\hline
\end{tabular}

Fonte: Elaborada pelos autores.

Observa-se que os valores médios dos resíduos dos accruals nos quatro modelos são similares e consistentes com os resultados dos estudos anteriores. Como principal variável de controle deste estudo, a dívida apresenta média de 0,317113, similar ao resultado apresentado por Ghosh e Moon (2010). As médias das variáveis: ciclo operacional (transformado em valores logarítmicos), Fluxo de Caixa e Prejuízo, também são semelhantes ao estudo anterior. Quanto ao Z-score, seu resultado maior que zero indica perspectiva de continuidade operacional, conforme Altman, Baidya, e Dias (1979). Desta forma é possível concluir que as empresas da amostra tendem a ser financeiramente saudáveis, pois apresentam média para o Z-score de 0,723397.

\section{ANÁLISE DOS RESULTADOS}

\subsection{Modelo Básico}

A partir das estimativas das variáveis para qualidade do lucro, conforme descrito na Seção 3, procedeu-se com a estimação de sua relação com a dívida. As estimativas da regressão considerando-se cada um dos quatro modelos de qualidade dos lucros são apresentados na Tabela 4. 
Os resultados indicam que a qualidade dos lucros possui relação não linear e côncava com a dívida, o que suporta a hipótese H1. Além disso, tal relação é robusta aos quatro modelos utilizados para se estimar a qualidade dos lucros. Especificamente, os coeficientes da forma quadrática da variável dívida sugerem que à medida que as empresas elevam seus níveis de endividamento, reduzem os níveis de accrual (consistente com evidências em Diamond (1991) e Billett et al. (2007)), o que seria decorrente de uma tentativa de reduzir custos de financiamento. Porém, a partir de certo nível de endividamento, devido às cláusulas de covenants, os ganhos advindos da redução de custos da dívida seriam mitigados pelos riscos de não cumprir as cláusulas, surgindo incentivos ao aumento dos accruals (Sweeney, 1994; DeFond \& Jiambalvo, 1994; Sun \& Rath, 2008).

A não-linearidade, então, sugere que os ganhos advindos da redução de custos da dívida podem estar sendo mitigados para empresas que já se encontram com elevados níveis de endividamento. Tal resultado é consistente com evidências obtidas por Ghosh e Moon (2010) e podem sugerir que os riscos de não cumprimento de cláusulas dos contratos de dívida (covenants) possam estar superando os benefícios de se reportar lucros de maior qualidade para empresas muito endividadas.

Por se tratar de um resultado em um país emergente com acesso mais restrito ao mercado de capitais e com menores prazos de financiamento, pesquisas que envolvem qualidade da informação contábil ressaltam uma outra justificativa para a relevância do nível de endividamento (Funchal \& Monte-Mor, 2016). Nesse caso, o nível de endividamento pode trazer informações associadas às decisões gerenciais de reportar lucros com maior ou menor qualidade, influenciando inclusive a previsão dos fluxos de caixa futuros (Smith, 1993; Ghosh \& Moon, 2010). Tal resultado apresenta também um diferencial em relação às análises feitas por Zamri, Rahman e Isa (2013), os quais investigaram apenas uma relação linear entre dívida e accruals para empresas da Malásia.

Considerando os efeitos na qualidade do lucro referentes às variáveis de controle, verifica-se que empresas maiores, com maior saúde financeira (Z-Score) e com maiores taxas de crescimento reportam lucros de maior qualidade. Por outro lado, empresas que possuem custos da dívida mais elevados reportam lucros com maior componente discricionário, o que segue consistente com resultados obtidos por Diamond (1991) e Sun e Rath (2008). As demais variáveis de controle não apresentaram influência robusta na qualidade do lucro na maioria das especificações.

Um ponto importante a ser destacado é o fato de que as métricas de accruals utilizadas nesse trabalho seguem as principais métricas utilizadas na literatura. Porém, estas métricas podem apresentar limitações ao não capturar aspectos relevantes do cálculo dos accruals.

De acordo com Larson, Sloan \& Zha Giedt (2017), as métricas baseadas em variação do capital de giro são menos significativas economicamente do que as métricas de accruals operacionais não correntes. Assim como métricas baseadas em fluxo de caixa, segundo os autores, medem de forma incompleta os accruals por não incorporar medidas de aquisições e desinvestimentos e/ou capitalizações do imobilizado. Deste modo, entende-se que os resultados do presente estudo devem ser interpretados com cautela, à luz das críticas recentes às medidas de accruals escolhidas. Este pode ser um dos motivos pelos resultados divergentes entre os modelos de Jones e Jones Modificado, baseados em variação do capital, versus os modelos de Dechow e Dichev e McNichols, que são baseados em flutuações do fluxo de caixa.

No Brasil, muitos covenants se baseiam em métricas de imobilização de ativos ou possuem cláusulas adicionais que os colocam como garantia em empréstimos de longo prazo, especialmente em função do fraco ambiente legal. Desta forma, os resultados sugerem que elevados níveis de endividamento poderiam levar os gestores a gerenciarem métricas que de alguma forma se relacionam à conta de imobilizado, gerando mais resíduos absolutos nos modelos de Jones e Jones Modificado, na medida que a dívida se eleva. Nesse sentido, entendemos que os nossos resultados trazem uma nova discussão para literatura, uma vez que o artigo de Ghosh e Moon (2010) utiliza apenas os modelos de Dechow e Dichev, alterado por McNichols, e o artigo de Zamri, Rahman e Isa (2013) medem a qualidade dos lucros por meio de métricas de gerenciamento reais de lucros. 
Tabela 4. Dívida e Accruals Discricionários

\begin{tabular}{|c|c|c|c|c|}
\hline Variáveis & Jones & Jones Modificado & Dechow e Dichev & McNichols \\
\hline Dívida & $(0.0499)$ & $(0.0504)$ & $(0.0283)$ & $(0.0257)$ \\
\hline \multirow[t]{2}{*}{ Dívida $^{2}$} & $0.317 * * *$ & $0.298 * * *$ & $0.0403 * *$ & $0.0328 * *$ \\
\hline & $(0.0447)$ & $(0.0443)$ & $(0.0190)$ & $(0.0165)$ \\
\hline \multirow[t]{2}{*}{ Ciclo Op. } & $-0.0214 * * *$ & $-0.0221 * * *$ & 0.00478 & 0.00267 \\
\hline & $(0.00758)$ & $(0.00744)$ & $(0.00361)$ & $(0.00325)$ \\
\hline \multirow[t]{2}{*}{ Tamanho } & $-0.0121 * * *$ & $-0.0132 * * *$ & $-0.00600^{* * *}$ & $-0.00742 * * *$ \\
\hline & $(0.00311)$ & $(0.00315)$ & $(0.00196)$ & $(0.00187)$ \\
\hline Fluxo de Caixa & $(0.0521)$ & $(0.0561)$ & $(0.0370)$ & $(0.0395)$ \\
\hline \multirow[t]{2}{*}{ Prejuízo } & -0.0195 & -0.0156 & $0.0156^{* *}$ & $0.0187 *$ \\
\hline & $(0.0133)$ & $(0.0140)$ & $(0.00734)$ & $(0.00697)$ \\
\hline \multirow[t]{2}{*}{ Custo da Dívida } & $0.0000504 * *$ & $0.0000809 * * *$ & 0.0000680 & $0.000258 * *$ \\
\hline & $(0.0000228)$ & $(0.0000237)$ & $(0.000101)$ & $(0.00011)$ \\
\hline \multicolumn{5}{|l|}{ Saúde Financeira } \\
\hline \multirow[t]{2}{*}{ Z-score } & $-0.0194 * *$ & $-0.0189 * *$ & $-0.0147 * * *$ & $-0.0135^{* *}$ \\
\hline & $(0.00807)$ & $(0.00813)$ & $(0.00560)$ & $(0.00542)$ \\
\hline \multirow[t]{2}{*}{ Idade } & -0.000201 & -0.000187 & $0.000331 * *$ & $0.000299 * *$ \\
\hline & $(0.000263)$ & $(0.000269)$ & $(0.000164)$ & $(0.00015)$ \\
\hline \multirow[t]{2}{*}{ ROA } & $-0.188^{*}$ & -0.155 & 0.0276 & $0.0763 *$ \\
\hline & $(0.108)$ & $(0.112)$ & $(0.0480)$ & $(0.0413)$ \\
\hline \multirow[t]{2}{*}{ Gov. Corporativa } & 0.00367 & 0.00256 & $0.0117 * *$ & 0.00635 \\
\hline & $(0.00769)$ & $(0.00803)$ & $(0.00481)$ & $(0.00429)$ \\
\hline \multirow[t]{2}{*}{ Auditada Big4 } & 0.0129 & 0.0146 & $-0.0172 * *$ & $-0.0161 * * *$ \\
\hline & $(0.00875)$ & $(0.00908)$ & $(0.00687)$ & $(0.00585)$ \\
\hline Dummy setor & Incluída & Incluída & Incluída & Incluída \\
\hline \multirow[t]{2}{*}{ Constante } & $0.439 * * *$ & $0.459 * * *$ & $0.133 * * *$ & $0.153 * * *$ \\
\hline & $(0.0767)$ & $(0.0766)$ & $(0.0394)$ & $(0.0372)$ \\
\hline Observações & 1256 & 1256 & 1049 & 1049 \\
\hline $\mathrm{R}^{2}$ Ajustado & 0.186 & 0.177 & 0.187 & 0.177 \\
\hline Estatística F & 12.650 & 16.335 & 7.321 & 13.407 \\
\hline
\end{tabular}

Fonte: Elaborada pelos autores.

Nota: Desvio-padrão robustos a heterocedasticidade e autocorrelação em parênteses.

Níveis de Significância: $* \mathrm{p}<0,10 ; * * \mathrm{p}<0,05 ; \mathrm{e}^{* * *} \mathrm{p}<0,01$.

\subsection{Regressão segmentada}

Os resultados da seção anterior são baseados em uma especificação não linear que inclui a Dívida e a Dívida2 na mesma regressão. Como teste de robustez, foi utilizada a especificação por meio de Spline como ferramenta estatística alternativa. Splines são funções de regressão segmentadas. O ponto de corte da segmentação é definido de acordo com o formato da relação da variável dependente com a independente. 
Assim, optamos por dividir a dívida em dois segmentos, usando como ponto de corte o ponto de inflexão da parábola estimada nas equações anteriores. A partir dos coeficientes estimados na seção 4.2, conclui-se que a relação entre a qualidade dos lucros e da dívida é curvilínea, sendo uma parábola côncava. O ponto de inflexão está em torno de 0,43 para o modelo de Jones (1991), 0,42 para o modelo de Jones Modificado (1995), 0,59 para o modelo de Dechow e Dichev (2002), e 0,54 para o modelo de McNichols (2002). O Gráfico 2, a seguir, ilustra essa relação. Observa-se no gráfico que apesar de os pontos e inflexão serem relativamente próximos, o efeito da dívida sobre os accruals é maior nos modelos Jones e Jones Modificado. Deve-se destacar que a diferença observada decorre do fato de que, ao contrário dos outros modelos baseados em fluxo de caixa, os modelos de Jones e Jones Modificado incorporam medidas de aquisições e desinvestimentos e/ou capitalizações do imobilizado. Assim, a diferença na sensibilidade dos modelos ao nível de endividamento reflete basicamente as diferenças no cálculo dos accruals e justamente por este motivo optamos por apresentar os resultados de todos os modelos.

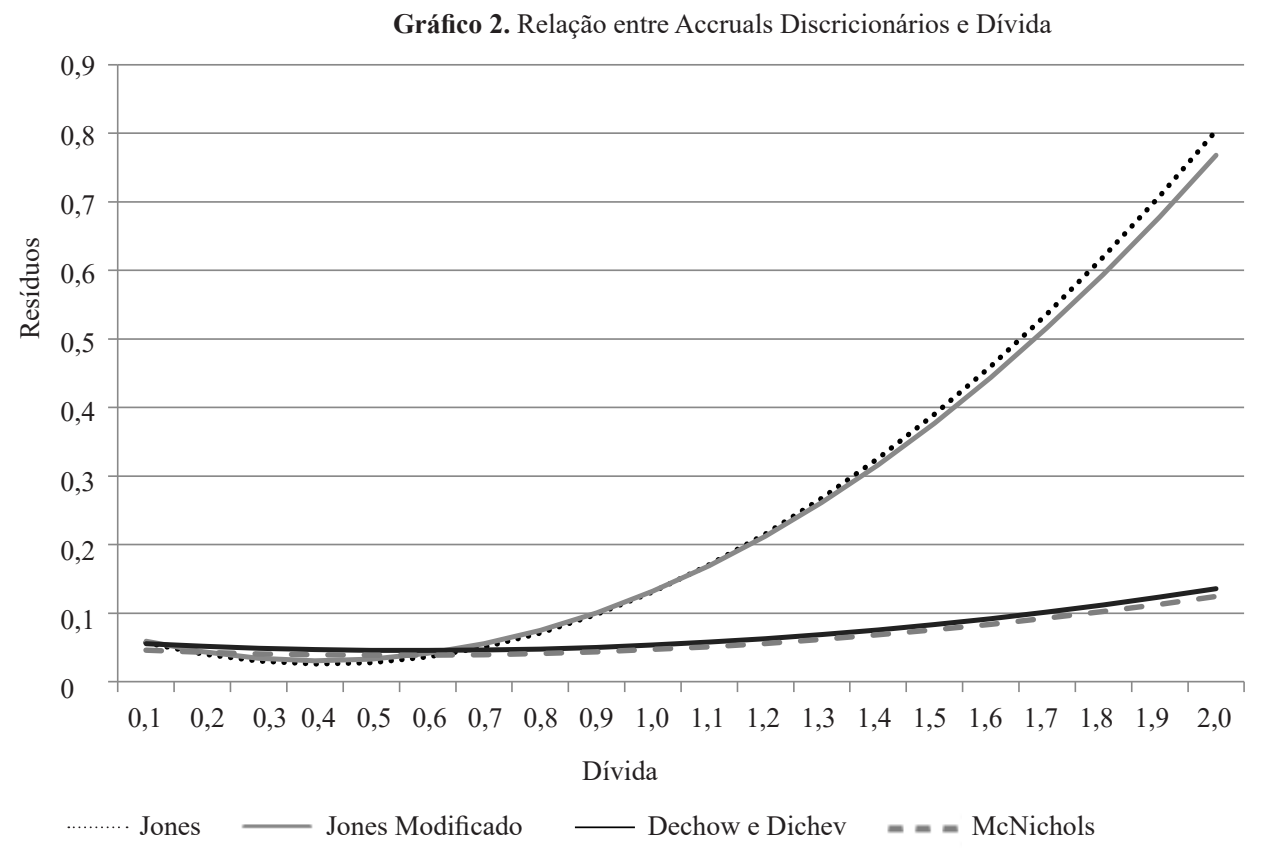

Fonte: Elaborado pelos autores.

Desta forma, utilizando como ponto de inflexão da dívida os respectivos pontos de Spline(Sp), estima-se o seguinte modelo:

$$
\begin{aligned}
& \text { Accruals Discricionários }_{i t}=\beta_{0}+\beta_{1} \text { Dívida }_{(0, S p)}+\beta_{2} \text { Dívida }_{(S p, I)}+\beta_{3} \text { Ciclo Operacional }_{i t}+\beta_{4} \text { Tamanho }_{i t}+ \\
& \beta_{5} \text { Receitas }_{\sigma i}+\beta_{6} \text { Fluxo de Caixa }_{\sigma i}+\beta 7 \text { Prejuizo }_{i}+\beta_{8} \text { Custo da Divida }_{i t}+\beta_{9} \text { Z-score }_{i t}+\beta_{10} \text { Crescimento }_{i t}+\beta_{11} \\
& \text { Margem Bruta }_{i t}+\beta_{12} \text { Idade }_{i t}+\beta_{13} \text { ROA }_{i t}+\beta_{14} \text { Gov. Corporativa }_{i t}+\beta_{15} \text { Auditada Big }_{i t}+\sum \beta_{j} \text { Setor }_{i}{ }_{i}+\varepsilon_{i t}
\end{aligned}
$$

Onde: $\operatorname{Dívida}(0, \mathrm{Sp})=$ dívida que se situa entre 0 e o ponto de Spline $\mathrm{Sp}$ (baixa); Dívida(Sp,1)= dívida superior ao ponto de Spline Sp (alta). Os resultados são apresentados na Tabela 5.

Ao estimar o modelo observa-se que os resultados, assim como apresentados na Tabela 4, indicam que somente as estimativas dos resíduos nos modelos de Jones e Jones modificado, em relação à dívida, são significativos. Novamente confirma-se parcialmente a relação não linear da dívida (H1). 
Tabela 5. Dívida e Qualidade dos Lucros: Regressão Segmentada

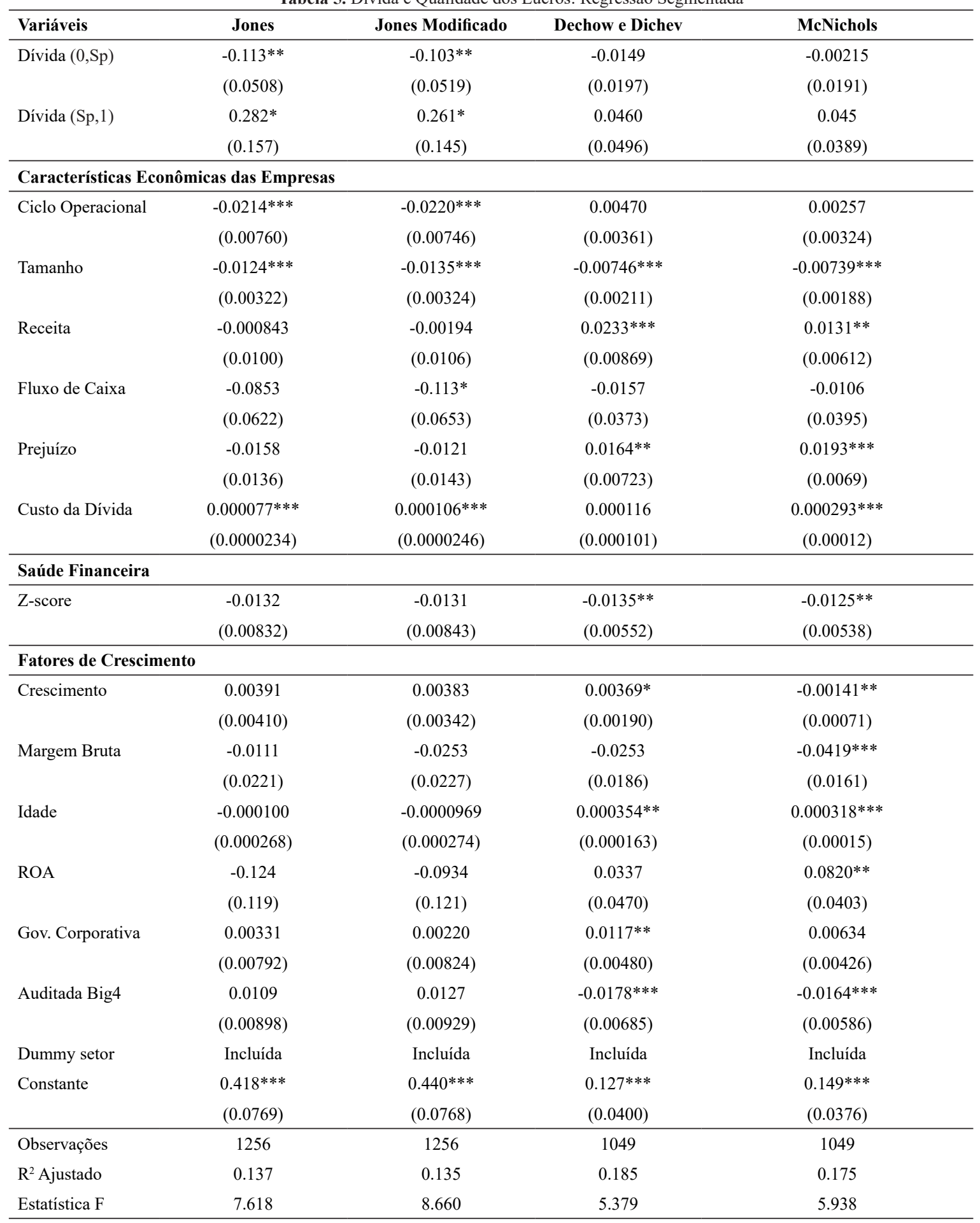

Fonte: Elaborada pelos autores.

Nota: A variável dependente de cada coluna é o resíduo estimado por meio dos modelos de accruals descrito na Seção 3 . Desvio-padrão robustos a heterocedasticidade e autocorrelação em parênteses.

Níveis de Significância: $* \mathrm{p}<0,10 ; * * \mathrm{p}<0,05 ; \mathrm{e} * * * \mathrm{p}<0,01$.

\subsection{Dívida de curto $x$ longo prazo}

Na Tabela 6 apresentam-se os resultados da relação entre a dívida de Curto Prazo e Longo Prazo com a qualidade dos lucros (H2). 
Tabela 6. Efeito da Dívida de Curto e Longo Prazo na Qualidade dos Lucros

\begin{tabular}{|c|c|c|c|c|}
\hline Variáveis & Jones & Jones Modificado & Dechow e Dichev & McNichols \\
\hline \multirow[t]{2}{*}{ Dívida Curto Prazo } & 0.00419 & 0.0404 & 0.00418 & -0.0698 \\
\hline & $(0.0721)$ & $(0.0721)$ & $(0.0778)$ & $(0.0602)$ \\
\hline \multirow[t]{2}{*}{ Dívida Curto Prazo² } & 0.0604 & 0.0381 & -0.00611 & 0.178 \\
\hline & $(0.142)$ & $(0.135)$ & $(0.185)$ & $(0.138)$ \\
\hline \multirow[t]{2}{*}{ Dívida Longo Prazo } & $-0.349 * * *$ & $-0.341 * * *$ & $-0.0714 * *$ & -0.0373 \\
\hline & $(0.0516)$ & $(0.0518)$ & $(0.0345)$ & $(0.0315)$ \\
\hline \multirow[t]{2}{*}{ Dívida Longo Prazo ${ }^{2}$} & $0.546^{* * *}$ & $0.525 * * *$ & $0.0857 * * *$ & $0.0558 *$ \\
\hline & $(0.0652)$ & $(0.0638)$ & $(0.0329)$ & $(0.0296)$ \\
\hline \multicolumn{5}{|c|}{ Características Econômicas das Empresas } \\
\hline \multirow[t]{2}{*}{ Ciclo Operacional } & $-0.0209 * * *$ & $-0.0221 * * *$ & 0.00451 & 0.00248 \\
\hline & $(0.00735)$ & $(0.00721)$ & $(0.00361)$ & $(0.00325)$ \\
\hline \multirow[t]{2}{*}{ Tamanho } & $-0.0114 * * *$ & $-0.0121 * * *$ & $-0.00708 * * *$ & $-0.00747 * * *$ \\
\hline & $(0.00316)$ & $(0.00320)$ & $(0.00207)$ & $(0.00187)$ \\
\hline \multirow[t]{2}{*}{ Receita } & -0.00425 & -0.00580 & $0.0226^{* *}$ & $0.01186^{*}$ \\
\hline & $(0.00947)$ & $(0.0104)$ & $(0.00881)$ & $(0.00614)$ \\
\hline \multirow[t]{2}{*}{ Fluxo de Caixa } & -0.0237 & -0.0532 & -0.00793 & -0.007 \\
\hline & $(0.0534)$ & $(0.0575)$ & $(0.0363)$ & $(0.0385)$ \\
\hline \multirow[t]{2}{*}{ Prejuízo } & $-0.0231 *$ & -0.0203 & $0.0146^{* *}$ & $0.0173 * *$ \\
\hline & $(0.0128)$ & $(0.0135)$ & $(0.00727)$ & $(0.00688)$ \\
\hline \multirow[t]{2}{*}{ Custo da Dívida } & $0.0000572 * *$ & $0.0000852 * * *$ & 0.0000569 & $0.000215^{*}$ \\
\hline & $(0.0000228)$ & $(0.0000239)$ & $(0.000105)$ & $(0.00011)$ \\
\hline \multicolumn{5}{|l|}{ Saúde Financeira } \\
\hline \multirow[t]{2}{*}{ Z-score } & $-0.0153^{*}$ & $-0.0153^{*}$ & $-0.0146 * *$ & $-0.0150 * * *$ \\
\hline & $(0.00827)$ & $(0.00831)$ & $(0.00571)$ & $(0.0056)$ \\
\hline \multicolumn{5}{|c|}{ Fatores de Crescimento } \\
\hline \multirow[t]{2}{*}{ Crescimento } & 0.00484 & 0.00473 & $0.00383 * *$ & $-0.00140^{*}$ \\
\hline & $(0.00387)$ & $(0.00324)$ & $(0.00191)$ & $(0.00073)$ \\
\hline \multirow[t]{2}{*}{ Margem Bruta } & -0.000738 & -0.0131 & -0.0238 & $-0.0431 * * *$ \\
\hline & $(0.0208)$ & $(0.0214)$ & $(0.0184)$ & $(0.0158)$ \\
\hline \multirow[t]{2}{*}{ Idade } & -0.000339 & -0.000331 & $0.000301 *$ & $0.000274 *$ \\
\hline & $(0.000262)$ & $(0.000267)$ & $(0.000165)$ & $(0.00015)$ \\
\hline \multirow[t]{2}{*}{ ROA } & $-0.200 *$ & -0.167 & 0.0237 & $0.0787^{*}$ \\
\hline & $(0.112)$ & $(0.116)$ & $(0.0492)$ & $(0.0422)$ \\
\hline \multirow[t]{2}{*}{ Gov. Corporativa } & 0.00161 & 0.000648 & $0.0115 * *$ & 0.006854 \\
\hline & $(0.00764)$ & $(0.00799)$ & $(0.00476)$ & $(0.0043)$ \\
\hline \multirow[t]{2}{*}{ Auditada por Big 4} & $0.0148 *$ & $0.0173^{*}$ & $-0.0164 * *$ & $-0.0155^{* * *}$ \\
\hline & $(0.00877)$ & $(0.00911)$ & $(0.00686)$ & $(0.00575)$ \\
\hline Dummy setor & Incluída & Incluída & Incluída & Incluída \\
\hline \multirow[t]{2}{*}{ Constante } & $0.418 * * *$ & $0.436 * * *$ & $0.130 * * *$ & $0.164 * * *$ \\
\hline & $(0.0773)$ & $(0.0772)$ & $(0.0401)$ & $(0.0377)$ \\
\hline Observações & 1256 & 1256 & 1049 & 1049 \\
\hline $\mathrm{R}^{2}$ Ajustado & 0.192 & 0.186 & 0.188 & 0.180 \\
\hline Estatística F & 13.377 & 16.728 & 12.665 & 10.901 \\
\hline
\end{tabular}

Fonte: Elaborada pelos autores

Nota: A variável dependente de cada coluna é o resíduo estimado por meio dos modelos de accruals descrito na Seção 3 . Desvio-padrão robustos a heterocedasticidade e autocorrelação em parênteses.

Níveis de Significância: $* \mathrm{p}<0,10 ; * * \mathrm{p}<0,05 ; \mathrm{e} * * * \mathrm{p}<0,01$.

Nota-se que os resultados estimados estabelecem que a relação não linear nas regressões dos quatro modelos é significativa apenas para a dívida de longo prazo, ainda que as evidências sejam pouco robustas para o modelo de McNichols. 
Assim, verifica-se que a relação não linear entre o volume de endividamento e a qualidade dos lucros está associada à dívida de longo prazo, e não à de curto prazo, confirmando H2. Tal resultado sugere que a decisão de incorrer nos custos de piora na qualidade dos lucros está associada à dívida de longo prazo, o que segue alinhado a resultados anteriores de que a rigidez na vinculação dos contratos da dívida pode resultar no gerenciamento de resultados (Ghosh \& Moon, 2010).

Nossos resultados vão ao encontro dos de Fung \& Goodwin (2013). Utilizando dados para o mercado americano, os autores estimaram uma relação positiva para dívidas de curto prazo, porém muito mais fraca para dívidas longas. Entretanto, os autores não investigam a possibilidade de não linearidade. A diferença entre aos resultados ilustra não só o efeito de não se incorporar a não linearidade nas estimativas, como também as diferentes características nos mercados de financiamento de longo e curto prazo no Brasil vis-à-vis o mercado norte-americano.

O resultado de nosso artigo segue também alinhado às outras evidências da literatura brasileira, tais como Silva (2008), o qual demonstra que as empresas brasileiras de capital aberto que têm dívidas de longo prazo estão sujeitas a uma série de covenants contábeis, o que pode ser explicado em função do ambiente legal com baixa efetividade jurídica (Almeida \& Dalmácio, 2015; Lopes \& Walker, 2008). Como as cláusulas contratuais que permitem a antecipação da dívida estão, em geral, associadas às dívidas de longo prazo, esses resultados contribuem para a literatura na medida em que evidenciam o papel das dívidas de longo prazo nas escolhas contábeis das empresas.

\section{CONSIDERAÇÕES FINAIS}

Estudos anteriores verificaram uma relação não linear entre dívida e qualidade dos lucros no mercado norte-americano. Este trabalho testou tal relação no cenário brasileiro e apresentou evidências de que as decisões gerenciais também estão associadas de forma não linear ao nível de endividamento em países emergentes, como é o caso do Brasil. Especificamente, infere-se de uma forma geral que: i) empresas pouco endividadas reportam lucros de maior qualidade, permitindo que tais empresas elevem sua capacidade de endividamento e reduzam o custo da dívida e; ii) empresas com elevados níveis de endividamento reportam lucros com maior componente discricionário. Tais resultados sugerem que os riscos de não cumprimento de cláusulas dos contratos de dívida (covenants) possam estar superando os benefícios de se reportar lucros de maior qualidade para empresas muito endividadas.

Adicionalmente, investigou-se qual tipo de dívida (curto ou longo prazo) influencia a qualidade do lucro. Se a empresa decide incorrer em custos associados ao aumento do gerenciamento em situações de autoendividamento devido às restrições impostas por covenants, então é mais provável que tais custos estejam sendo gerados por dívidas de longo prazo, já que podem sofrer antecipação por quebra de cláusulas contratuais. Os resultados obtidos corroboram com tais expectativas ao indicarem que a relação não linear entre dívida e qualidade dos lucros está relacionada à dívida de longo prazo, e não à dívida de curto prazo.

Tais indícios contribuem para a literatura e estendem as discussões de trabalhos como o de Ghosh e Moon (2010) na medida em que evidenciam o papel das dívidas de longo prazo nas decisões contábeis das empresas. Por se tratar de um resultado em um país emergente com acesso mais restrito ao mercado de capitais e com menores prazos de financiamento, ressalta-se outra justificativa para a utilização do nível de endividamento em pesquisas que envolvem qualidade da informação contábil.

Os resultados obtidos apresentam ainda contribuições à literatura de governança que analisa o papel do monitoramento exercido pelos contratos de dívida (Grossman \& Hart, 1982; Diamond, 1991; Francis et al., 2005. Bharath et al, 2008; Funchal e Monte-Mor, 2016). Nesse caso, nossos resultados estendem tal literatura ao apresentar evidências de que a política de endividamento interfere não só na política operacional das empresas, mas também nas decisões gerenciais de reportar lucros.

$\mathrm{Na}$ prática, as estimativas apontadas nesse artigo podem servir de embasamento para a um maior detalhamento dos contratos de dívida e maior proteção ao credor. A relação côncava aponta os níveis de endividamento nos quais os accruals são mais elevados e, portanto, as estimativas de fluxo de caixa mais imprecisas.

Assim, agentes financiadores (bancos e credores) podem utilizar esses cutoffs para requerer cláusulas de proteção ou taxas de juros que os compensem pelos riscos resultantes do aumento (ou redução) dos níveis de accruals. Da mesma forma, empresas podem mensurar em média qual o seu nível de accruals ideal para que não incorra em taxas e requerimentos elevados e que acabem por elevar o seu custo de capital médio ponderado. 
Este trabalho abre alguns pontos com potencial de discussão em futuras pesquisas: i) os modelos de accruals utilizados, embora se tratem das principais métricas utilizadas na literatura, estão baseados na variação do capital de giro e fluxo de caixa, e não capturam accruals operacionais não correntes, além de medidas de aquisições e desinvestimentos e/ou capitalizações do imobilizado.

No Brasil, como muitos covenants se baseiam em métricas de imobilização de ativos ou possuem cláusulas adicionais que os colocam como garantia em empréstimos de longo prazo, é possível que outros tipos de gerenciamento possam contribuir com a dinâmica não linear entre dívida de longo prazo e qualidade dos lucros; ii) embora restrições contratuais sejam uma das principais argumentações para tal relação não linear, estudos mais detalhados se fazem necessários para que sejam investigadas em profundidade as cláusulas dos contratos de dívida, a fim de se identificar quais tipos de covenants/contratos aumentam a probabilidade de alteração da dinâmica de gerenciamento das empresas; iii) estudos mais recentes apresentam evidências de que o IFRS aumentou o número de cláusulas contratuais no Brasil. Nesse caso, é possível que tais aumentos tenham se dado exatamente para limitar o engajamento dos gestores com relação à decisões gerenciais; iv) a partir do desenvolvimento de novas técnicas de coleta em larga escala de informações contidas nas demonstrações financeiras, tal como Perlin (2017) será possível extrair diferentes maturidades do perfil das dívidas das empresas e explorar a não linearidade em função dos prazos de maturidade da dívida, um dos pontos que destacamos nesse trabalho. Tais resultados poderiam contribuir para a relevância das dívidas de longo prazo nas decisões contábeis das empresas.

\section{REFERÊNCIAS}

Almeida, J. E. F., \& Dalmácio, F. Z. (2015). The effects of corporate governance and product market competition on analysts' forecasts: Evidence from the Brazilian capital market. The International Journal of Accounting, 50(3), 316-339. DOI: https://doi.org/10.1016/j.intacc.2015.07.007

Altman, E.I., Baidya, T. K., \& Dias, L.M.R. (1979). Previsão de problemas financeiros em empresas. Revista de Administração de Empresas, 19(1), 17-28. DOI: http://dx.doi.org/10.1590/S0034-75901979000100002

Beiruth, A. X., Fávero, L. P. L., Murcia, F., Almeida, J. E. F., \& Brugni, T. (2017) Structural Changes in Covenants Through the Adoption of IFRS in Brazil. Accounting Forum, 41 (3), 147-160. DOI: https://doi.org/10.1016/j. accfor.2017.06.004

Bharath, S. T., Sunder, J., \& Sunder, S. V. (2008). Accounting quality and debt contracting. The Accounting Review, 83(1), 1-28.

Billett, M. T., King, T. D., \& Mauer, D. C. (2007). Growth Opportunities and the Choice of Leverage, Debt Maturity, and Covenants. Journal of Finance, 62, 697-730. DOI: https://doi.org/10.2308/accr.2008.83.1.1

Chiang, S. Kleinman, G. \& Lee, P. (2017). Do non-staggered board elections matter to earnings quality and the value relevance of earnings and book value?. Review of Accounting and Finance, 16(1), 46-66. DOI: https:// doi.org/10.1108/RAF-01-2015-0006

Citron, D.B. (1992). Financial Ratio Covenants in UK Bank Loan Contracts and Accounting Policy Choice. Accounting and Business Research, 22(88). DOI: https://doi.org/10.1080/00014788.1992.9729448

Cormier, D., Demaria, S., \& Magnan, M. (2017). Beyond earnings: do EBITDA reporting and governance matter for market participants? Managerial Finance, 43(2), 193-211. DOI: https://doi.org/10.1108/MF-07-2016-0205

Cupertino, C. M. (2013). Gerenciamento de resultados por decisões operacionais no mercado de capitais brasileiro. Tese (Doutorado em Administração) - Programa de PósGraduação em Administração, Universidade Federal de Santa Catarina, Florianópolis. Disponível em: https://repositorio.ufsc.br/handle/123456789/122592

Dechow, P. M., \& Dichev, I. D. (2002). The quality of accruals and earnings: The role of accrual estimation errors. The Accounting Review, 77(1), 35-59. DOI: https://doi.org/10.2308/accr.2002.77.s-1.35

Dechow, P. M., Sloan, R. G., \& Sweeney, A. P. (1995). Detecting earnings management. Accounting review, 70(2), 193-225. Retrieved from http://www.jstor.org/stable/248303

Dechow, P., et al. (2010). Understanding earnings quality: A review of the proxies, their determinants and their consequences. Journal of accounting and economics, 50(2), 344-401. DOI: https://doi.org/10.1016/j. jacceco.2010.09.001 
DeFond, M. L., \& Jiambalvo, J. (1994). Debt covenant violation and manipulation of accruals. Journal of accounting and economics, 17(1), 145-176. DOI: https://doi.org/10.1016/0165-4101(94)90008-6

Desender, K. A., Aguilera, R. V., Crespi, R., \& Garcia-Cestona, M. (2013). When does ownership matter? Board characteristics and behavior. Strategic Management Journal, 34(7), 823-842. DOI: https://doi.org/10.1002/ smj.2046

Diamond, D. (1991). Monitoring and reputation: the choice between bank loans and directly placed debt. Journal of Political Economy, 99(4), 689-721. DOI: https://doi.org/10.1086/261775

Dichev, I. D. et al. (2012). Earnings quality: Evidence from the field. Journal of Accounting and Economics, 56(2), 1-33. DOI: https://doi.org/10.1016/j.jacceco.2013.05.004

Doukakis, L. C. (2014). The effect of mandatory IFRS adoption on real and accrual-based earnings management activities. Journal of Accounting and Public Policy, 33(6), 551-572. DOI: https://doi.org/10.1016/j. jaccpubpol.2014.08.006

Fama, E. F., \& Jensen, M. C. (1983). Separation of ownership and control. The journal of law and Economics, 26(2), 301-325. DOI: https://doi.org/10.1086/467037

Francis, J., LaFond, R., Olsson, P., \& Schipper, K. (2005). The market pricing of accruals quality. Journal of accounting and economics, 39(2), 295-327. DOI: https://doi.org/10.1016/j.jacceco.2004.06.003

Funchal, B., \& Monte $\square$ Mor, D. S. (2016). Corporate Governance and Credit Access in Brazil: The Sarbanes $\square$ Oxley Act as a Natural Experiment. Corporate Governance: An International Review, 24(5), 528-547. DOI: https://doi.org/10.1111/corg.12151

Fung, S. Y., \& Goodwin, J. (2013). Short-term debt maturity, monitoring and accruals-based earnings management. Journal of Contemporary Accounting \& Economics, 9(1), 67-82. DOI: https://doi.org/10.1016/j. jcae.2013.01.002

Ghosh, A. A., \& Moon, D. (2010). Corporate debt financing and earnings quality. Journal of Business Finance \&

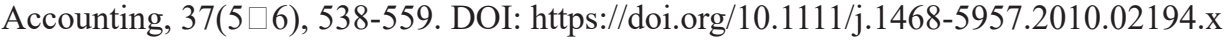

Graham, J. R., Li, S., \& Qiu, J. (2008). Corporate misreporting and bank loan contracting. Journal of Financial Economics, 89(1), 44-61. DOI: https://doi.org/10.1016/j.jfineco.2007.08.005

Grossman, S. J., \& Hart, O. D. (1982). Corporate financial structure and managerial incentives. In The economics of information and uncertainty (pp. 107-140). University of Chicago Press.

Gu, Z., Lee, C. W. J., \& Rosett, J. G. (2005). What determines the variability of accounting accruals? Review of Quantitative Finance and Accounting, 24(3), 313-334. DOI: https://doi.org/10.1007/s11156-005-6869-1

Harris, M., \& Raviv, A. (1990). Capital structure and the informational role of debt. The Journal of Finance, 45(2), 321-349. DOI: https://doi.org/10.1111/j.1540-6261.1990.tb03693.x

Healy, P. M., \& Palepu, K. G. (2001). Information asymmetry, corporate disclosure, and the capital markets: A review of the empirical disclosure literature. Journal of accounting and economics, 31(1), 405-440. DOI: https://doi.org/10.1016/S0165-4101(01)00018-0

Healy, P. M., \& Wahlen, J. M. (1999). A review of the earnings management literature and its implications for standard setting. Accounting horizons, 13(4), 365-383. DOI: https://doi.org/10.2308/acch.1999.13.4.365

International Monetary Fund (IMF). (2015). World economic outlook: a survey by the staff of the International Monetary Fund. Washington, DC: International Monetary Fund.

Jensen, M. C. (1986). Agency costs of free cash flow, corporate finance, and takeovers. The American economic review, 76(2), 323-329. Retrieved from http://www.jstor.org/stable/1818789

Jensen, M. C., \& Meckling, W. H. (1976). Theory of the firm: Managerial behavior, agency costs and ownership structure. Journal of financial economics, 3(4), 305-360. DOI: https://doi.org/10.1016/0304-405X(76)90026-X

Jha, A. (2013). Earnings management around debt-covenant violations-An empirical investigation using a large sample of quarterly data. Journal of Accounting, Auditing \& Finance, 28(4), 369-396. DOI: https://doi. org/10.1177/0148558X13505597 
Joia, R. M. (2012). Adoção de IFRS e gerenciamento de resultado nas empresas brasileiras de capital aberto. Dissertação (Mestrado em Ciências) - Faculdade de Economia, Administração e Contabilidade de Ribeirão Preto, Universidade de São Paulo, Ribeirão Preto. Dsiponível em: http://www.teses.usp.br/teses/ disponiveis/96/96133/tde-06122012-155637/pt-br.php

Joia, R. M., \& Nakao, S. H. (2014). Adoção de IFRS e gerenciamento de resultado nas empresas brasileiras de capital aberto. Revista de Educação e Pesquisa em Contabilidade, 8(1), 22-38. DOI: http://dx.doi. org/10.17524/repec.v8i1.1014

Jones, J. J. (1991). Earnings management during import relief investigations. Journal of accounting research, 193228. DOI: https://doi.org/10.2307/2491047

Klann, R. C. (2011) Gerenciamento de resultados: análise comparativa de empresas brasileiras e inglesas antes e após a adoção das IFRS. Tese (Doutorado em Ciências Contábeis e Administração) - Programa de PósGraduação em Ciências Contábeis da Universidade Regional de Blumenau, Blumenau. Disponível em: http:// www.bc.furb.br/docs/TE/2011/349758_1_1.PDF

Larson, C. R., Sloan, R. G., \& Zha Giedt, J. (2017). Defining, Measuring and Modeling Accruals: A Guide for Researchers. Working paper, SSRN n. 2952601. DOI: https://dx.doi.org/10.2139/ssrn.2952601

Leland, H. E. (1994). Corporate debt value, bond covenants, and optimal capital structure. The journal of finance, 49(4), 1213-1252. DOI: https://doi.org/10.1111/j.1540-6261.1994.tb02452.x

Lopes, A. B., \& Walker, M. (2008). Firm-level incentives and the informativeness of accounting reports: An experiment in Brazil. Working paper. SSRN n. 1095781. DOI: https://dx.doi.org/10.2139/ssrn.1095781

Martinez, A. L. (2013). Gerenciamento de resultados no Brasil: um survey da literatura. Brazilian Business Review, 10(4), 1-31. DOI: http://dx.doi.org/10.15728/bbr.2013.10.4.1McNichols, M. F. (2002). Discussion of the quality of accruals and earnings: multiples. Journal of Accounting Research, 40(1), 135-72. DOI: https://doi.org/10.2308/accr.2002.77.s-1.61

Perlin, M. (2017). GetDFPData: Reading Annual Financial Reports from Bovespa's DFP, FRE and FCA System. R package version 0.5. Disponível em: https://CRAN.R-project.org/package=GetDFPDataSengupta, P. (1998). Corporate disclosure quality and the cost of debt. Accounting review, 459-474. Retrieved from http://www. jstor.org/stable/248186

Silva, A. H. C. (2008). Escolha de práticas contábeis no Brasil: uma análise sob a ótica da hipótese dos covenants contratuais. 159f. Tese (Doutorado em Ciências Contábeis) - Programa de Pós Graduação em Ciências Contábeis, Universidade de São Paulo, São Paulo. Disponível em:http://www.teses.usp.br/teses/ disponiveis/12/12136/tde-16012009-120147/publico/Tese_Adolfo_Silva_2008.pdf

Smith, C.W. Jr. (1993). A Perspective on Accounting-Based Debt Covenant Violations. The Accounting Review, 68(2), 289-303. Retrieved from http://www.jstor.org/stable/248402

Soderstrom, N. S., \& Sun, K. J. (2007). IFRS adoption and accounting quality: a review. European Accounting Review, 16(4), 675-702. DOI: https://doi.org/10.1080/09638180701706732

Sweeney, A. P. (1994), Debt Covenant Violations and Managers' Accounting Responses. Journal of Accounting and Economics, 17, 281-308. DOI: https://doi.org/10.1016/0165-4101(94)90030-2

Sun, L., \& Rath, S. (2008). Fundamental determinants, opportunistic behavior and signaling mechanism: an integration of earnings management perspectives. International Review of Business Research Papers, 4(4), 406-420. Disponível em: http://www.bizresearchpapers.com/32-Lansun.pdf

Van Tendeloo, B., \& Vanstraelen, A. (2005). Earnings management under German GAAP versus IFRS. European Accounting Review, 14(1), 155-180. DOI: https://doi.org/10.1080/0963818042000338988

Watts, R. L., \& Zimmerman, J. L. (1986). Positive accounting theory.

Zamri, N., Rahman, R. A., \& Isa, N. S. M. (2013). The impact of leverage on real earnings management. Procedia Economics and Finance, 7, 86-95. DOI: https://doi.org/10.1016/S2212-5671(13)00222-0.

\section{Como citar este artigo}

Costa, C.M., Matte, A.M. \& Monte-Mor, D.S. (2018 ). Endividamento e Decisões Contábeis: A Relação Não Linear entre Dívida e Qualidade dos Lucros. Revista de Contabilidade e Organizações, 12:e137077. DOI: http://dx.doi.org/10.11606/issn.1982-6486.rco.2018.137077 